\title{
The Effect of Head Loading on Cervical Spine in Manual Laborers
}

\author{
Bharat R. Dave, Ajay Krishnan, Ravi Ranjan Rai, Devanand Degulmadi, Shivanand Mayi \\ Department of Spine Surgery, Stavya Spine Hospital and Research Institute, Ahmedabad, India
}

\section{Study Design: A prospective case-control study.}

Purpose: To determine the effect of axial loading on the cervical spine when weights are carried on the head.

Overview of Literature: Traditionally, carrying weights on the head has been a common practice in developing countries. The laborers working in agriculture, construction, and other industries, as well as porters at railway platforms, are required to lift heavy weights. Since controversy exists regarding carrying weights on the head, we decided to evaluate its effect on the cervical spine.

Methods: The study comprised 62 subjects. Of this number, 32 subjects (group A) were unskilled laborers from the construction industry; the other 30 subjects (group B) were in the control group and had never previously carried heavy weights on their heads. Cervical spine radiographs were taken for all the 62 subjects. Subjects in group A were asked to carry a load (approximately $35 \mathrm{~kg}$ ) on their heads and walk for about $65 \mathrm{~m}$, with their cervical spine radiographs taken afterward.

Results: The mean ages of patients in groups $A$ and B were 27.17 and 25.75 years, respectively. The mean cervical lordosis observed in group $A\left(18.96^{\circ}\right)$ was dramatically less compared with group $B\left(25.40^{\circ}\right)$, showing a further decrease in head loading $\left(3.35^{\circ}\right)$. Five subjects had a reversal of lordosis $\left(-5.61^{\circ}\right)$. A statistically significant reduction in disc height and listhesis was observed when the load was carried on the head with a further decrease after walking with the load. Accelerated degenerative changes, particularly affecting the upper cervical spine, were observed in head loaders.

Conclusions: Carrying a load on the head leads to accelerated degenerative changes, which involve the upper cervical spine more than the lower cervical spine and predisposes it to injury at a lower threshold. Thus, alternative methods of carrying loads should be proposed.

Keywords: Neck pain; Spondylosis; Spine; Carrying; Occupational diseases

\section{Introduction}

Carrying loads on the head is a traditional practice in India by laborers in construction industry and agriculture. There is a paucity of literature on the effects of carrying weights on the head, and controversy exists regarding this being detrimental to the cervical spine [1]. This study aims to identify the effect of loads on the cervical spine when weights are carried on the head.

Received Jul 5, 2019; Revised Oct 30, 2019; Accepted Nov 28, 2019

Corresponding author: Ravi Ranjan Rai

Stavya Spine Hospital and Research Institute, Near Nagari Hospital, Mithakhali, Ellisbridge, Ahmedabad-380006, Gujarat, India

Tel: +91-9726820898,+91-7926483000, E-mail: drravirai84@gmail.com 


\section{Materials and Methods}

\section{Participants and methods}

This study was conducted in 2010 after approval from the Ethics and Scientific Committee, Sheth Vadilal Sarabhai Medical Research Foundation Trust (Reg. no., 14/217/93TU.V). Written informed consent was obtained from all individuals participating in the study. The study comprised laborers habituated to carrying loads in group A and control subjects in group B. Group A comprised laborers, aged 20 to 40 years, who worked in the construction industry with a minimum of 6 months' experience, routinely carrying loads on their heads. Those with any spinal or systemic diseases were excluded from the study. Group B comprised subjects who had never carried loads on their heads. Hospital nursing and clerical staff were included as subjects in this group.

Unloaded lateral view radiographs of the cervical spine were taken in neutral, flexion, and extension positions for all subjects in both groups. Then, subjects in group A were asked to carry an approximately $35 \mathrm{~kg}$ weight (12 bricks on a plywood plate) (Fig. 1) and walk a distance of approximately $65 \mathrm{~m}$ ( $55 \mathrm{~m}$ in the open air $+5 \mathrm{~m}$ on a slope +5 $\mathrm{m}$ indoor) (Fig. 2). Lateral cervical spine radiographs were taken for group A subjects with a load and again after walking the prescribed distance while carrying a load.

Radiographs were analyzed for cervical lordosis movements in flexion and extension, as well as changes after

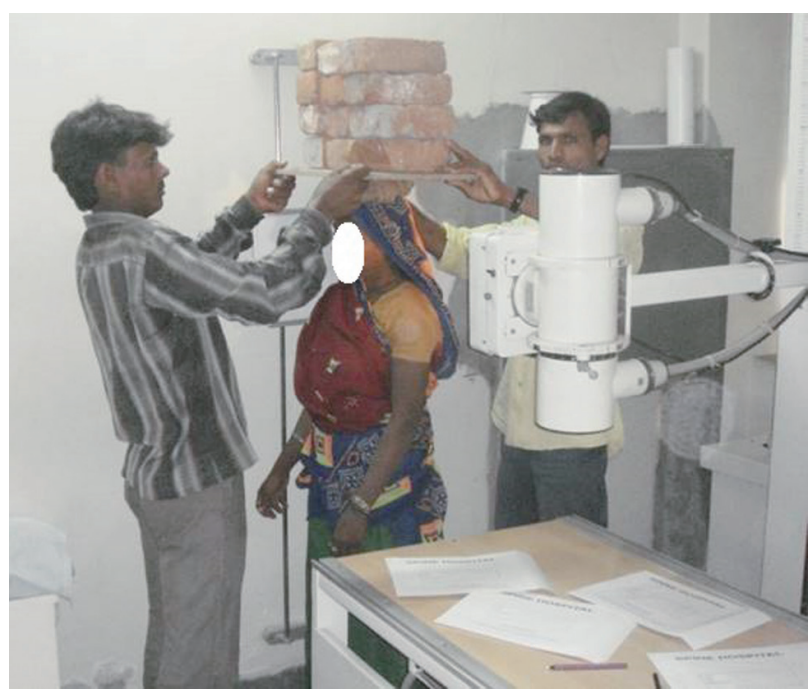

Fig. 1. Cervical spine of a subject in group A being loaded with a heavy object on the head (12 bricks, approximately $35 \mathrm{~kg}$ ). Written informed consent was obtained from all individuals participating in the study. carrying the load. Cervical lordosis was measured between C2 lower endplate and C7 lower endplate. Height of intervertebral discs and translation of vertebral bodies were noted.

\section{Statistical analysis}

IBM SPSS ver. 20.0 software (IBM Corp., Armonk, NY, USA) was used for data analysis. We used the chi-square test for evaluating categorical data and the Mann-Whitney $U$-test for continuous data. Average values are presented in the tables as mean \pm standard deviation. The difference was considered significant when the $p$-value was less than 0.05 .

\section{Results}

The study was conducted on 62 subjects: 32 laborers in group A and 30 controls in group B. The demographic profiles of subjects in both groups are shown in Table 1.

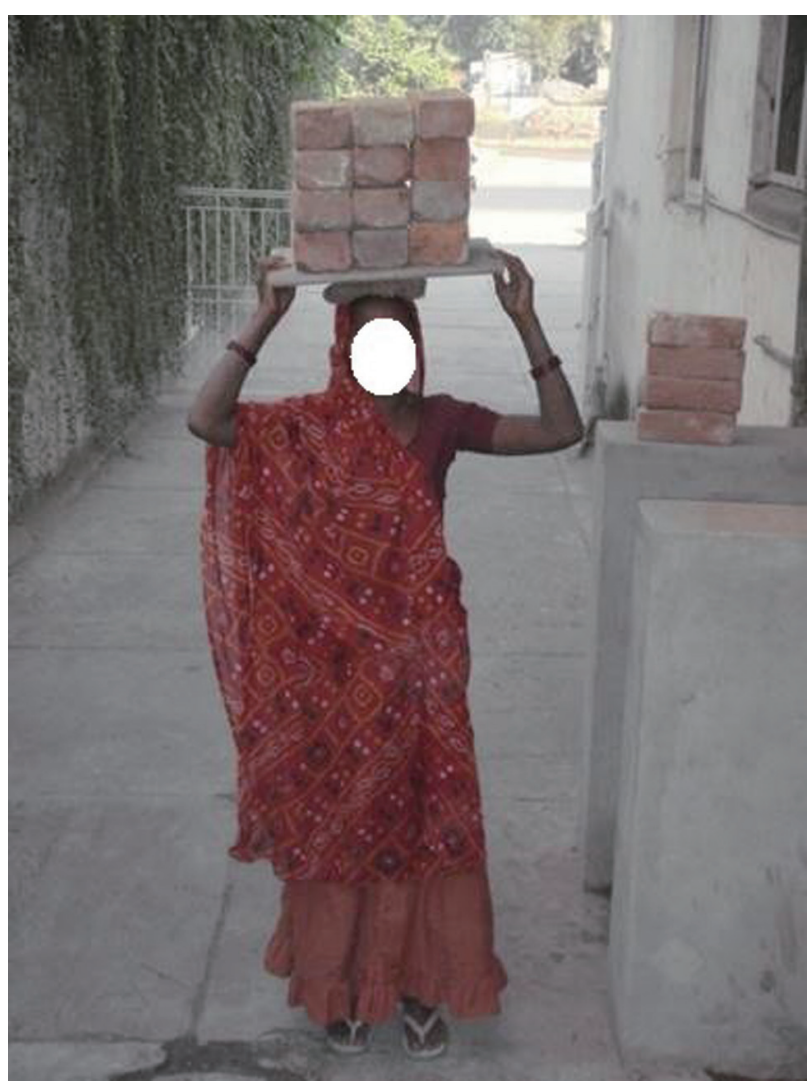

Fig. 2. A subject in group A walking with a load on the designated path (approximately $65 \mathrm{~m}$, which includes $55 \mathrm{~m}$ in the open air $+5 \mathrm{~m}$ on a slope $+5 \mathrm{~m}$ indoor). Written informed consent was obtained from the participant. 
Subjects in group A had 5- to 20-year working experience in the construction industry. Table 2 shows the radio-

Table 1. Showing demographic characteristics of both groups

\begin{tabular}{lrc} 
Characteristic & Group A & Group B \\
\hline Age $(\mathrm{yr})$ & $27.17 \pm 5.55$ & $25.75 \pm 4.26$ \\
Height $(\mathrm{m})$ & $1.49 \pm 0.13$ & $1.65 \pm 0.09$ \\
Body weight $(\mathrm{kg})$ & $51.61 \pm 1.88$ & $59.40 \pm 17.46$ \\
Work experience (yr) & $8 \pm 5.21$ & - \\
\hline
\end{tabular}

Values are presented as mean \pm standard deviation.
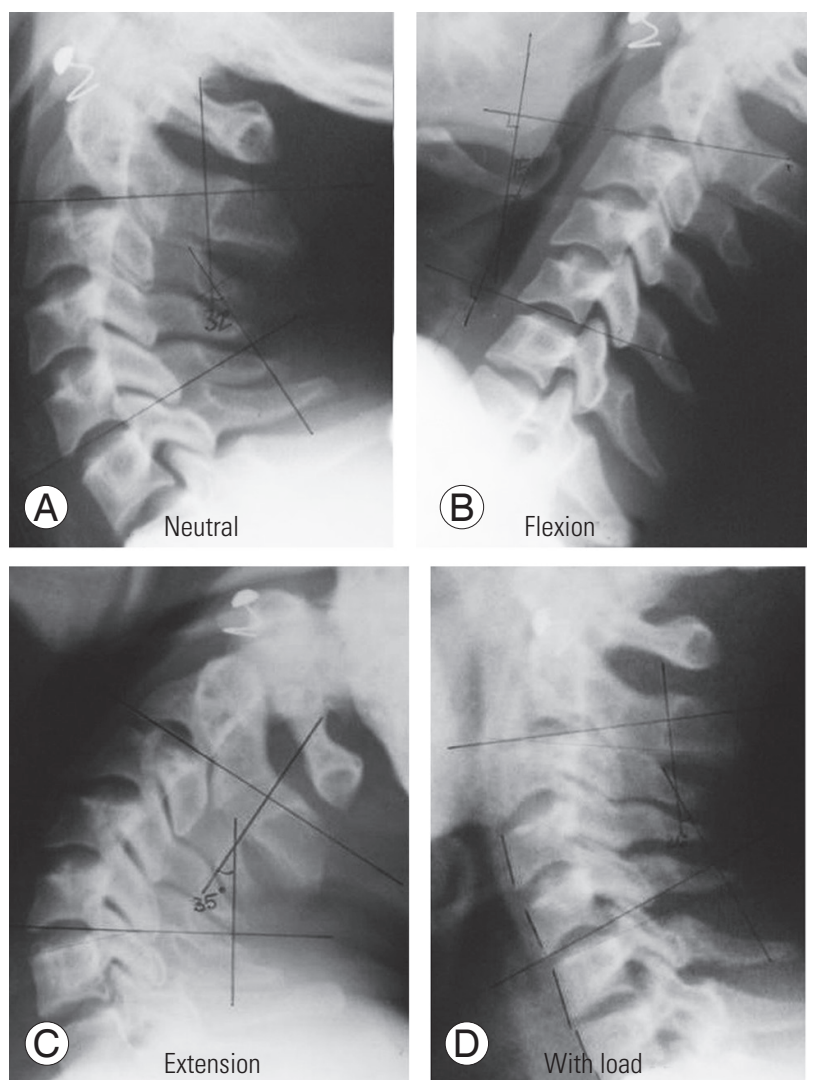

Fig. 3. Radiographs of a subject in group A showing a neck in neutral (A), flexion (B), and extension (C) and with head loading (D). Most of the flexion/ extension movements were observed in the upper cervical spine with minimal movements in the lower cervical spine. Also, the straightening of cervical lordosis and reduction of disc height were seen on head loading. graphic measurements. Compared with control group B $( \pm 25.40)$, mean cervical lordosis in neutral position was observed to be less in group A $( \pm 18.96)$. Compared with the control group, group A demonstrated less flexion but more extension. Most of the movements were observed in the upper cervical spine with minimal movements in the lower cervical spine (Fig. 3). All subjects in the control group were observed to have good flexion and extension movements. All subjects in group A were observed to have a minor translatory displacement in a dynamic radiographic examination. Five subjects (19\%) in group A had $>3 \mathrm{~mm}$ anterior displacement during flexion at minimum one level (Fig. 4). In the control group, no abnormal translation was observed on flexion except in two subjects who had a mild anterior translatory displacement of vertebrae during flexion. Both subjects were asymptomatic, with one having a congenital fusion of $\mathrm{C} 2$ and $\mathrm{C} 3$ vertebrae.

For group A, mean cervical lordosis decreased to $3.35 \pm 3.26$ after loading the cervical spine, and it further

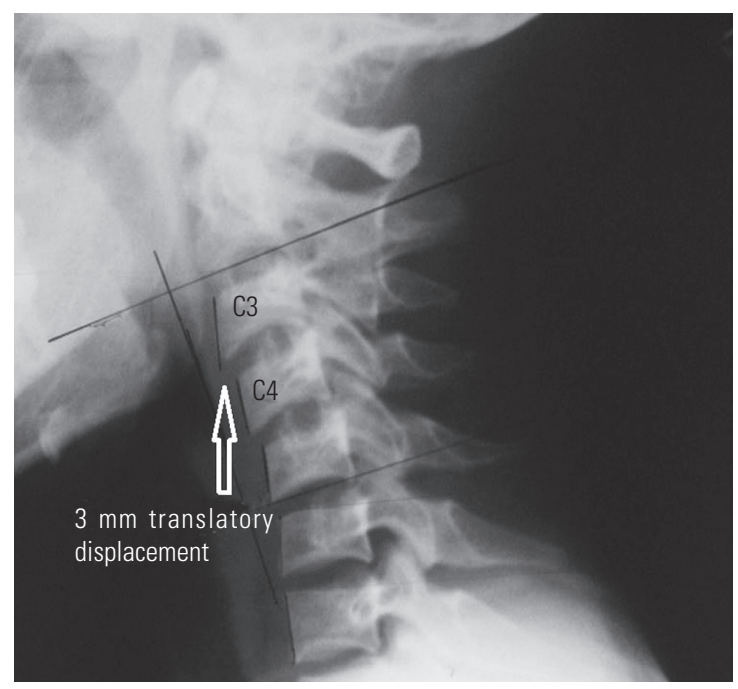

Fig. 4. Radiograph of a subject while carrying a load on the head. A major translation was observed at C3-4 and C4-5 on head loading (arrow).

Table 2. Showing the cervical spine (C2-C7) lordosis and its changes with head loading

\begin{tabular}{lccc} 
Mean cervical lordosis & Group A $(n=32)$ & Group B (n=30) & $p$-value \\
Neutral $\left({ }^{\circ}\right)$ & $18.96 \pm 6.71$ & $25.40 \pm 7.10$ & 0.012 \\
\hline Flexion $\left(^{\circ}\right)$ & $16.70 \pm 5.82$ & $10.25 \pm 6.31$ & 0.034 \\
\hline Extension $\left({ }^{\circ}\right)$ & $30.91 \pm 6.24$ & $21.23 \pm 6.89$ & 0.022 \\
With weight $\left(^{\circ}\right)$ & $3.35 \pm 3.26$ & - & - \\
With weight and after walking $\left(^{\circ}\right)$ & $-5.61 \pm 2.69$ & \\
\hline
\end{tabular}

Values are presented as mean \pm standard deviation. 


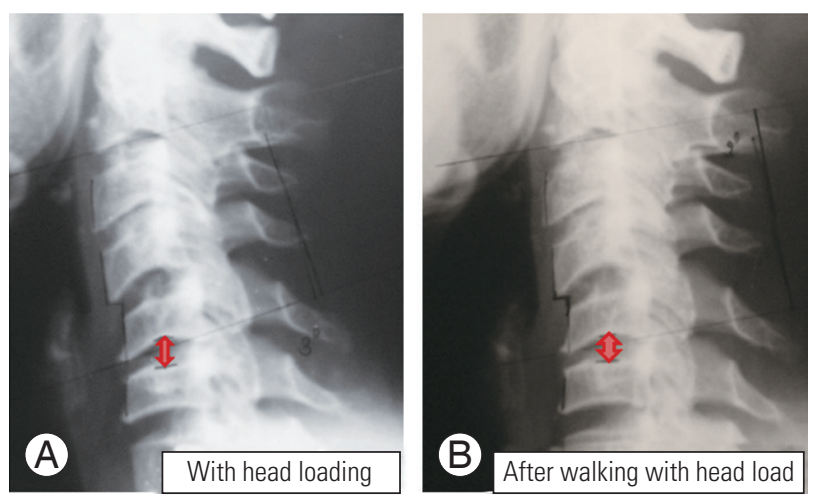

Fig. 5. Radiographs of a subject with head loading (A) and after walking a designated distance with the load (B). This maneuver shows the instantaneous effect of walking with a load on the cervical spine biomechanics (arrow). Disc height reduction is seen to be further exaggerated after walking with the load (arrow).

decreased to $-5.6 \pm 2.69$ after walking the prescribed distance. Compared with the one in a neutral unloaded condition, a significant loss of lordosis was noticed when the cervical spine was loaded, with five subjects having a reversal of lordosis. A remarkable reduction in disc height was noticed when a load was carried on the head, with further reduction after walking with the load (Fig. 5).

\section{Discussion}

Carrying a load on the head has been shown to have detrimental effects on the cervical spine [2]. However, workers in the construction industry and agriculture, as well as railway porters, continue to carry loads on their heads as an integral part of their job. According to a survey in 20092010, there are around 465 million workers in India, with the majority (94\%) being employed in the unorganized sector [1]. There seems to be some awareness among these workers about safety at the workplace; however, the importance of their health condition continues to be ignored. The Ministry of Labor has put an upper limit on the permissible weight that can be carried by a worker. However, no specific notification exists against carrying weights on the head. There is a lack of awareness, as well as scientific evidence, about the detrimental effects of head loading on the cervical spine. In contrast, several studies have shown that carrying a load on the head causes the least deviation from normal gait as compared with carrying on the shoulder or hand [3]. Another study recommends a higher safe load carrying limit on the head than that permissible on the back [1]. A thorough understanding of the biomechan- ics of the cervical spine and the effect of head loading on these biomechanics and any attendant degenerative process would enable us to understand the true effects of repeated axial loading of the spine.

The spine is a complex structure that functions to protect the spinal cord and support loads in numerous postures and positions. The normal cervical spine motion exhibits an anterior-posterior translation during flexion and extension. The motion segments of the cervical spine are complex joints. Each joint consists of three compartments-the disc and two facets-along with multiple ligamentous structures. The kinematic and load support capacities of the motion segment vary significantly as a function of the spinal level, the direction of motion, the direction of load applied, and temporal exposure characteristics. These biomechanical properties of the spine may be altered by trauma and degeneration [4]. Along with aging, various other factors can significantly accelerate the degenerative process and the biomechanical functioning of the spine. Tissue damage can occur because of acute or chronic trauma. Acute trauma is understood as a single force that exceeds the tolerance limit of the tissue. Another mechanism of tissue damage is the repeated cumulative loading of the tissues. Repeated loading by moderate force can cause the tissue to strengthen and adapt to the load. However, repetitive loading without proper rest time can cause tissue degeneration, leading to a weakening of the structure and its failure at lower levels of trauma.

In his study, Levy [5] observed that cervical spine injuries in porters' necks were more likely to involve the upper cervical spine rather than the lower cervical spine, as is the usual trend in trauma. To understand the reasons behind such a deviation in injury pattern, Levy [5] subjected seven randomly selected porters to radiographic examination with a load on their heads. He observed that, when loaded, the vertebral bodies and intervertebral discs assumed a vertical position, which would relieve some of the stress on the ligaments and intrinsic muscles. However, the disc was compressed, and forward tilting of the vertebral body on diseased discs reduced the amount of overriding of corresponding facet joints, thereby predisposing the spine to injury.

Joosab et al. [6] studied the cervical radiographs of loaders and non-loaders. They observed a major decrease in the angle of lordosis in loaders with no significant difference in spinal canal diameter. A decrease in disc height was observed with age, which was most remarkable at the 
5th intervertebral disc. Although the loader group exhibited no such correlation with age, loading appeared to cause a redistribution of changes in disc height, with the 1st intervertebral disc showing changes similar to those seen in the 5th intervertebral disc. Jager et al. [2] evaluated the relationship between load carrying on the head and development of degenerative changes in the cervical spine. They observed a higher prevalence of degenerative changes in loaders as compared with non-loaders, with the highest prevalence at $\mathrm{C} 5 / 6$, followed by $\mathrm{C} 4 / 5$ and C6/7.

Joosab et al. [6] found no major difference in canal diameter, whereas the studies of both Taitz [7] and Echarri and Forriol [8] demonstrated a narrow medullary canal with degenerative changes in head loaders. Echarri and Forriol [8] observed degenerative changes in $13.9 \%$ of wood bearers in cranial vertebrae as compared with only $2.3 \%$ in controls. They also observed listhesis in $20.8 \%$ of wood bearers as compared with $2.3 \%$ of controls, with C4 involvement in more than half the cases.

The observations of this study are concurrent with the above literature. Cervical lordosis in a neutral position of the neck was observed to be less in group A subjects as compared with control subjects in group B. A major decrease in cervical lordosis was observed with head loading, with further straightening of cervical spine and reversal of lordosis on walking with a head load. Loss of cervical lordosis and change in cervical sagittal alignment have been shown to have adverse implications on quality of life scores [9]. Progressive cervical kyphosis leads to the development of myelopathy by forcing the spinal cord against the vertebral bodies, inducing anterior cord pathology, as well as increasing the longitudinal cord tension due to the cord being tethered by the dentate ligaments and cervical nerve roots $[10,11]$.

Developmental spinal stenosis is a static factor of spinal cord compression, and vertebral instability is a dynamic factor that exacerbates this injury [12]. In this study, dynamic radiographic examination revealed minor translation of vertebral bodies in all loaders, whereas only two control subjects showed such translation. Major translation (3-4 mm) was observed in five loaders $(19 \%)$ on head loading. Meanwhile, intervertebral instability is considered to be a dynamic factor that exacerbates the spinal cord compression caused by developmental spinal stenosis [12]. Alizada et al. [13] has described cervical instability as a stage of the cervical degenerative process. During this

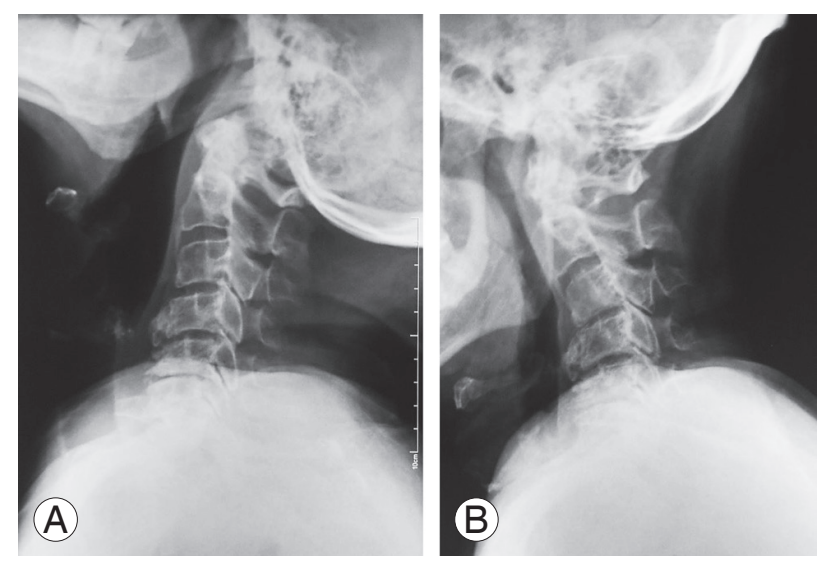

Fig. 6. (A, B) Dynamic radiographs of a head loader. Reduced disc height and flexion/extension movements are seen in the lower cervical spine. Most of the flexion/extension movements were observed to be occurring above C4. Reversal of cervical lordosis and restriction of extension movements were also observed.

stage, the overall cervical motion and intervertebral segmental movements show abnormal pathological changes.

Loaders in this study were subjected to radiographic examination while carrying around $35 \mathrm{~kg}$ loads on their heads. Noticeable reduction in disc height was characteristically seen on head loading. These loaders were then asked to walk a distance of $65 \mathrm{~m}$, and radiographs were repeated with the load still on their heads. Further decrease in disc space was observed after walking with the weight. These observations suggested instantaneous changes in the cervical spine when the head was loaded. The reversal of cervical lordosis, segmental instability, and reduced disc height observed in this study in head loaders are consistent with accelerated degenerative changes in the cervical spine (Fig. 6).

Thus, carrying a load on the head markedly accelerates the degenerative process in the cervical spine, thereby making these loaders vulnerable to consequences of cervical spondylosis, including neurological compromise at an early age, as well as increased susceptibility to cervical spine injuries.

Since the study involved human subjects, the number of subjects and the loads carried on their heads were limited by the recommended safety limits of the region and the institutional ethical committee. This study, however, was able to convincingly document the accelerated degenerative changes of the cervical spine in loaders, as well as the effects of acute loading. However, it would have been more useful if long-term changes induced by carrying loads were documented, which would go beyond the 
scope of this research.

\section{Conclusions}

Carrying a load on the head leads to a loss of cervical spine lordosis, reduction in disc height, remarkable translation of vertebrae, and redistribution of degenerative changes to the upper cervical spine, accelerating the cervical spine degenerative process and decreasing the threshold of injury in head loaders. Cervical spine degenerative disorders in appropriate settings may be considered as an occupational disease. Since carrying a load on the head is detrimental to the cervical spine, it is recommended to use alternative methods of carrying loads.

\section{Conflict of Interest}

No potential conflict of interest relevant to this article was reported.

\section{ORCID}

Bharat R. Dave: https://orcid.org/0000-0003-2668-5848

Ajay Krishnan: https://orcid.org/0000-0001-9808-2371

Ravi Ranjan Rai: https://orcid.org/0000-0002-0873-6907

Devanand Degulmadi: https://orcid.org/0000-0002-7263-9706

Shivanand Mayi: https://orcid.org/0000-0003-3753-8712

\section{References}

1. Sharma R, Kamboj K, Bhardwaj J. Gender response and safe carrying load limit for sugar industry workers. Int J Occup Saf Ergon 2019;25:51-60.

2. Jager HJ, Gordon-Harris L, Mehring UM, Goetz GF, Mathias KD. Degenerative change in the cervical spine and load-carrying on the head. Skeletal Radiol 1997;26:475-81.

3. Guha Thakurta A, Iqbal R, De A. The influence of three different load carrying methods on gait parameters of Indian construction workers. MOJ Anat Physiol 2017;3:113-6.
4. Marras WS. Biomechanics of the spinal motion segment. In: Herkowitz HN, Garfin SR, Eismont FJ, Bell GR, Balderston RA, editors. Rothman-Simione the spine. 6th ed. Philadelphia (PA): Elsevier; 2011. p. 91-118.

5. Levy LF. Porter's neck. Br Med J 1968;2:16-9.

6. Joosab M, Torode M, Rao PV. Preliminary findings on the effect of load-carrying to the structural integrity of the cervical spine. Surg Radiol Anat 1994;16:393-8.

7. Taitz C. Anatomical observations of the developmental and spondylotic cervical spinal canal in South African blacks and whites. Clin Anat 1996;9:395-400.

8. Echarri JJ, Forriol F. Effect of axial load on the cervical spine: a study of Congolese woodbearers. Int Orthop 2002;26:141-4.

9. Ames CP, Blondel B, Scheer JK, et al. Influence of spinal deformity on management and outcome of cervical spondylotic myelopathy: cervical radiographical alignment: comprehensive assessment techniques and potential importance in cervical myelopathy. Spine 2013;38:S149-60.

10. Shimizu K, Nakamura M, Nishikawa Y, Hijikata S, Chiba K, Toyama Y. Spinal kyphosis causes demyelination and neuronal loss in the spinal cord: a new model of kyphotic deformity using juvenile Japanese small game fowls. Spine (Phila Pa 1976) 2005;30:2388-92.

11. Chavanne A, Pettigrew DB, Holtz JR, Dollin N, Kuntz C 4th. Spinal cord intramedullary pressure in cervical kyphotic deformity: a cadaveric study. Spine (Phila Pa 1976) 2011;36:1619-26.

12. Nishida N, Kato Y, Imajo Y, Kawano S, Taguchi T. Biomechanical analysis of cervical spondylotic myelopathy: the influence of dynamic factors and morphometry of the spinal cord. J Spinal Cord Med 2012;35:256-61.

13. Alizada M, Li RR, Hayatullah G. Cervical instability in cervical spondylosis patients: significance of the radiographic index method for evaluation. Orthopade 2018;47:977-85. 